\title{
El ocio como práctica promotora de salud mental en la comunidad: relato de experiência
}

\section{The leisure as a promoter practice in the mental health in the community: experience report \\ O lazer como prática promotora de saúde mental na comunidade: relato de experiência}

\author{
Janaína Paula Calheiros Pereira Sobral ${ }^{1}$, Alana Maiara Brito \\ Bibiano $^{2}$, Nívia Madja dos Santos Silva ${ }^{3}$, Jocelene Gonçalves de \\ Almeida4, Mariana Gomes Lima Avelino5 ${ }^{5}$ Amanda Maria \\ Monteiro Ferreira ${ }^{6}$
}

\begin{abstract}
${ }^{1}$ Enfermeira, Mestranda em Enfermagem, Universidade Federal de Alagoas. Maceió, Alagoas - Brasil.
${ }^{2}$ Fisioterapeuta, Mestre em gerontologia, Universidade Federal de Pernambuco. Recife - Pernambuco Brasil.

${ }^{3}$ Psicóloga, Especialista em Saúde do Adulto e do Idoso, Universidade Federal de Alagoas. Maceió, Alagoas Brasil.

${ }^{4}$ Profissional de Educação Física, Especialista em Saúde da Família, Universidade Estadual de Ciências da Saúde de Alagoas. Maceió, Alagoas - Brasil.

${ }^{5}$ Terapeuta Ocupacional, Especialista em Saúde da Família, Universidade Estadual de Ciências da Saúde de Alagoas. Maceió, Alagoas - Brasil.

${ }^{6}$ Nutricionista, Mestranda em Ensino na saúde e tecnologia, Universidade Estadual de Ciências da Saúde de Alagoas. Maceió, Alagoas - Brasil.

Cómo citar este artículo en edición digital: Sobral, J. P. C. P., Bibiano, A. M. B., Silva, N. M. S., Almeida, J. G., Avelino, M. G. L. E Ferreira, A. M. M. (2018). El ocio como práctica promotora de salud mental en la comunidad: relato de experiência. Cultura de los Cuidados (Edición digital), 22(52). Recuperado de http://dx.doi.org/10.14198/cuid.2018.52.17
\end{abstract}

Correspondência: Residencial Allegro, Avenida Sebastião Correia da Rocha, 1113. Bloco 04, Apt. 301, Bairro Tabuleiro do Martins. CEP: 57061-410 - Maceió (AL), Brasil

Correo electrónico: nainacalheiros2@gmail.com

Recibido: 03/04/2018; Aceptado: 09/06/2018



\begin{abstract}
Leisure is one of the conditions and health determinants and it participates in the health-disease process, especially in the context of mental health. Thus, the aim of this study was to describe the experience of multidisciplinary residents in family health in the planning and implementation of
\end{abstract}

mental health promotion actions through leisure activities in the community adscript in a Family Health Unit in Maceió, Alagoas. It was observable during the process of territorialisation, the lack of leisure devices and spaces reception to the demands of mental health of the population, and it was carried out various actions, through weekly 
meetings in order to create recreational spaces, interaction and media, in addition to encouraging sustainability and promote income generation. It was noticed that the leisure activities provided greater community involvement from socializing moments, increased formation of bond between the population and the health team, increasing self-esteem, improving care for the body and mind, and stimulated income generation and care for the environment through recycled material recycling workshops.

Keywords: Mental health, nursing, leisure activities, primary health care, health promotion.

\section{RESUMO}

O lazer é um dos condicionantes e determinantes da saúde e participa do processo saúde-doença, em especial, no contexto da saúde mental. Diante disso, o objetivo deste trabalho foi descrever a experiência dos residentes multiprofissionais em saúde da família no planejamento e execução de ações de promoção de saúde mental através de atividades de lazer na comunidade adscrita em uma Unidade de Saúde da Família de Maceió-Alagoas. Foi observada, durante o processo de territorialização, a ausência de dispositivos de lazer e espaços de acolhimento para as demandas de saúde mental da população, e com isso foram realizadas diversas ações, através de encontros semanais, no intuito de criar espaços de lazer, interação e comunicação social, além de estimular a sustentabilidade e fomentar a geração de renda. Percebeu-se que as ações de lazer proporcionaram maior envolvimento com a comunidade a partir dos momentos de socialização, uma maior formação de vínculo entre a população e a equipe de saúde, aumentando a autoestima, melhorando o cuidado com o corpo e a mente, e estimulou a geração de renda e o cuidado com o meio ambiente através das oficinas de reaproveitamento de material reciclável.

Palavras-chave: Saúde mental, enfermagem, atividades de lazer, atenção primária à saúde, promoção da saúde.

\section{RESUMEN}

El ocio es una de las condicionantes y determinantes de la salud e incide del proceso salud-enfermedad, en especial, en el contexto de la salud mental. El objetivo de este trabajo fue describir la experiencia de los residentes multiprofesionales en salud de la familia en la planificación y ejecución de acciones de promoción de salud mental a través de actividades de ocio en la comunidad adscrita en una Unidad de Salud de la Familia de Maceió-Alagoas. Se observó durante el proceso de territorialización la ausencia de dispositivos de ocio y espacios de acogida para las demandas de salud mental de la población, y con ello se realizaron diversas acciones, a través de encuentros semanales, con el fin de crear espacios de ocio, interacción y comunicación social, además de estimular la sostenibilidad y fomentar la generación de ingresos. Se percibió que las acciones de ocio proporcionaron mayor implicación con la comunidad a partir de los momentos de socialización, una mayor formación de vínculo entre la población y el equipo de salud, aumentando la autoestima, mejorando el cuidado con el cuerpo y la mente, y, estimuló la generación de ingresos y el cuidado con el medio ambiente a través de los talleres de reaprovechamiento de material reciclable.

Palabras clave: Salud mental, enfermería, actividades de ocio, atención primaria a la salud, promoción de la salud. 


\section{INTRODUÇÃO}

O lazer é considerado como o conjunto de ocupação às quais o indivíduo pode entregar-se de livre e espontânea vontade, seja para repousar, seja para divertir-se, recrear-se e entreter-se, ou ainda para desenvolver sua informação ou formação desinteressada, sua participação social voluntária ou sua livre capacidade criadora, após livrar-se ou desembaraçar-se das obrigações profissionais, familiares e sociais (Dumazedier, 1999).

Faz-se oportuno destacar que é um dos prazeres e que, portanto, situa-se nos fatores fundamentais para o bem-estar (Tinsley e col., 1985). Por ser um dos condicionantes e determinantes da saúde (Brasil, 1990) participa do processo saúde-doença, em especial, no contexto da saúde mental, pois as atividades socializantes realizadas como forma de divertimento e apoio social promovem bem-estar mental (Pondé e col., 2003) ao possibilitar novas interações e modificar o cotidiano, fazendo com que os aspectos físicos, mentais e sociais tenham resultados favoráveis (Souza e col., 2009).

O lazer possibilita desenvolver as habilidades do convívio social como a solidariedade e respeito por si e pelo outro, favorecendo a emancipação humana em oposição ao simples uso do tempo livre. No contexto das condições de vida e saúde interessa, ainda, um olhar atento para as situações de vulnerabilidade dos sujeitos para alterações de saúde provocadas pela ausência do lazer, sobretudo em comunidades que não apresentam esse dispositivo em seu território (Bacheladenski e col., 2010).

É importante e necessário conhecer o território que constitui a área de abrangência de uma Unidade de Saúde da Família (USF), pois somente assim poderá ser identificada a forma como as pessoas vivem, adoecem e morrem, para, então, fundamentar uma proposta de intervenção (Mafra e col., 2004). A Atenção à Saúde Mental deve ser responsabilidade de todos os profissionais de saúde; e a Atenção Básica $(\mathrm{AB})$ por ser porta de entrada para o Sistema Único de Saúde (SUS) deve desenvolver nas suas práticas intervenções em saúde mental que são construídas no cotidiano dos encontros entre profissionais e usuários, em que ambos criam novas ferramentas e estratégias para compartilhar e construir juntos o cuidado em saúde (Brasil, 2013).

O lazer possibilita ainda, novas interações e modifica o cotidiano, fazendo com que os aspectos físicos, mentais e sociais tenham resultados favoráveis para a saúde (Baldissera e col., 2012). Diante disso, o objetivo do presente trabalho foi descrever a experiência dos residentes multiprofissionais em saúde da família no planejamento e execução de ações de promoção de saúde mental através de atividades de lazer na comunidade adscrita em uma USF de Maceió - AL.

\section{METODOLOGIA}

Trata-se de um relato de experiência, descritivo, desenvolvido pelos residentes multiprofissionais em saúde da família da Universidade Estadual de Ciências da Saúde de Alagoas (UNCISAL), durante o período de maio de 2014 a dezembro de 2015. A referida equipe de residentes é composta por sete categorias profissionais, a saber: Educação Física, Enfermagem, Fisioterapia, Nutrição, Odontologia, Psicologia e Terapia Ocupacional que atuaram em conjunto na área de abrangência da Estratégia Saúde da Família (ESF), da USF Dr. Hélvio José de Farias Auto, localizada no II Distrito Sanitário de Saúde do Município de Maceió, Alagoas. 
Este trabalho foi resultado do processo de territorialização desenvolvido para identificar, entre outros aspectos, as potencialidades e fragilidades da comunidade adscrita na USF em relação aos determinantes e condicionantes da saúde. Nesse caminho, pôde-se observar a ausência de dispositivos de lazer e espaços de acolhimento para as demandas de saúde mental da população, sendo representada, em sua maioria, por mulheres de meia-idade ou idosas que se sentiam ociosas ou restritas às tarefas domésticas, com pouca socialização e com características de humor deprimido. Dessa forma, evidenciou-se a demanda para o planejamento estratégico de encontros em que a promoção da saúde ultrapassasse a perspectiva de prevenir e/ou tratar doenças, possibilitando maior bemestar mental e social, bem como uma maior autonomia dos sujeitos.

As ações planejadas foram intituladas de "Pingo Feliz", em alusão ao nome histórico e cultural da comunidade, a saber, "Comunidade Pingo D'Água". As atividades desenvolvidas foram voltadas para todas as faixas etárias: crianças, jovens, adultos e idosos, e ocorreram uma vez por semana nos espaços comunitários disponíveis no território, como associação de moradores e salão de festas. Uma das características era a rotatividade dos participantes, que procuravam se inserir de livre e espontânea vontade, conforme o interesse no tipo de atividade a ser executada.

\section{RELATO E DISCUSSÃO}

As ações desenvolvidas na comunidade foram diversas, e tiveram o intuito de criar espaços de lazer, interação e comunicação social, além de estimular a sustentabilidade e fomentar a geração de renda. As temáticas das atividades realizadas foram: jogos de bingo; book fotográfico para as mulheres da comunidade; dinâmicas de reflexão sobre autoestima; cinema; karaokê; lanche coletivo; circuito de massagens; oficina de pintura e reciclagem de garrafas; confecção de porta recados e porta canetas através de rolos de papel higiênico e palitos de picolé; oficina de artesanato para construção de guirlanda de natal com especiarias; jogos de mímica; momento de beleza com esfoliação e aplicação de máscara de argila na face; amigo secreto; chá de fraldas com dinâmicas diversificadas; passeios na praia, no parque municipal; entre outros.

Com o artesanato, por exemplo, trabalhouse desde a coordenação motora e conhecimento intelectual até o resgate de sentimentos, emoções e criatividade, auxiliando significativamente no processo de reabilitação e inclusão social dos usuários com sofrimento psicossocial (Pedroza e col., 2012).

A maior parte do material utilizado para a execução dessas atividades foi custeada pelos próprios residentes, sendo essa uma das dificuldades para a realização das ações, a exemplo de passeios que demandavam além de custeio financeiro, infraestrutura para aquelas pessoas que tinham dificuldades de locomoção. Entretanto, devido ao envolvimento da população com as atividades, a comunidade passou a colaborar, o que demonstrou a capacidade de inclusão que as atividades de lazer possuem. Outra dificuldade encontrada foi com relação às oficinas de artesanato, devido às burocracias para realizar parcerias. Com isso, as oficinas foram realizadas pelos residentes explorando habilidades individuais para que a própria população passasse a oferecer essas oficinas a partir de potencialidades/habilidades encontradas em seu meio. 
O lazer apresenta três funções na vida das pessoas: função de descanso, de divertimento e de desenvolvimento. $\mathrm{O}$ descanso libera-se da fadiga. Nesse sentido, o lazer funciona como um reparador dos desgastes físicos, mentais e emocionais, provocados pelas tensões das obrigações diárias e particularmente do trabalho. A segunda função compreende divertimento, recreação e entretenimento, dando suporte ao que se pode chamar, de higiene mental. Já a função de desenvolvimento da personalidade permite uma participação social mais livre, uma prática de uma cultura desinteressada do corpo, da sensibilidade e da razão, além da formação prática e técnica, e oferece novas possibilidades de agrupamentos recreativos, culturais e sociais, fomentando o desenvolvimento livre de atitudes e de criar novas formas de aprendizagem voluntária. (Dumazedier, 2004). Diante disso, as três funções estavam presentes, em graus variados, em todas as atividades promovidas pela equipe de residentes.

Baseando-se nas ações desenvolvidas, pôde-se observar que as atividades de lazer proporcionaram maior envolvimento com a comunidade a partir desses momentos de socialização. Houve relatos do quão bem àquelas ações fizeram para a vida das pessoas, aumentando a autoestima, melhorando o cuidado com o corpo e a mente, e proporcionando geração de renda e cuidado com o meio ambiente através das oficinas de reaproveitamento de material reciclável. Esses momentos caracterizaramse por apresentar o compartilhamento de experiências, das histórias da vida dos participantes, o que viabilizou a formação de vínculo entre a população e a equipe de saúde; além de aumentar a procura por serviços de promoção de saúde na comunidade (grupos de educação em saúde).

Assim, a importância das mais diversas práticas de atividades que caracterizam o lazer, significa considerá-lo como tempo privilegiado para vivência de valores que venham contribuir nas mudanças sociais necessárias a todas as comunidades. (Ribas, 1995)

Como se pode observar também no estudo de Loss (2008), que com o uso do lazer em saúde mental objetiva-se desenvolver aspectos motores e psicomotores como orientação espacial, equilíbrio, percepções melhoradas, capacidades físicas, com a finalidade de conservar o prazer de movimentar-se, melhorando suas qualidades de motricidade, estimulando o crescimento, reduzindo distúrbios de coordenação e aumentando a autoconfiança.

\section{CONSIDERAÇÕES FINAIS}

As experiências com as ações realizadas pelos residentes mostraram que o cuidado com a saúde mental não deve ser centralizado na doença e que ações de promoção de saúde, através de atividades de lazer, podem gerar bons resultados na situação de saúde de uma população.

Dessa forma, houve uma preocupação da equipe em superar o entendimento que a saúde mental se relaciona com diagnóstico e tratamento de doenças mentais e problemas de comportamento, buscando trabalhar diversos temas que buscassem empoderar os sujeitos a tomarem decisões assertivas sobre sua vida enquanto indivíduo e na vida em sociedade, além de proporcionar espaços de convivência e de lazer, trocas afetivas e acolhimento das demandas no grupo. 


\section{REFERÊNCIAS}

- Bacheladenski, M. S. \& Matiello, J. E. (2010). Contribuições do campo crítico do lazer para a promoção da saúde. Ciênc. Saúde coletiva, 15(5) 2569-2579.

- Baldissera, V. D. A. \& Bueno, S. M. V. (2012). O lazer e a saúde mental das pessoas hipertensas: convergência na educação para a saúde. Rev esc enferm, 46(2) 380-387.

- Brasil. (2013). Saúde mental. Secretaria de Atenção à Saúde. Departamento de Atenção Básica/ Departamento de Ações Programáticas Estratégicas. Brasília: Ministério da Saúde. Recuperado de http://189.28.128.100/dab/docs/portaldab/publicac oes/caderno 34.pdf.

- Brasil. (1990). Lei n. 8.080, de 19 de setembro de 1990. Dispõe sobre as condições para a promoção, proteção e recuperação da saúde, a organização e o funcionamento dos serviços correspondentes e dá outras providências. Diário Oficial [da] República Federativa do Brasil. Brasilia: Ministério da Saúde. Recuperado de http://conselho.saude.gov.br/legislacao/lei8080 19 0990.htm.

- Dumazedier, J. (1999). A revolução cultural do tempo livre. São Paulo: Nobel.

- Dumazedier, J. (2004). Lazer e Cultura Popular. São
Paulo: Perspectiva.

- Loss, S. N. (2008). Deficiência mental e lazer: um relato de experiência. Revista Digital, 13(127). 32-36.

- Mafra, M. R. P. \& Chaves, M. M. N. (2004). O processo de territorialização e a atenção à saúde no programa saúde da família. Fam. Saúde. Desenv, 6(2) 127-133.

- Pedroza, A.P., Oliveira, F.B., Fortunato, M.L. \& Soares, P.F.C. (2012). Articulação saúde mental e economia solidária: relato de projeto de inclusão social. Rev Rene, 13(2) 454-462.

- Pondé, M. P. \& Caroso, C. (2003). Lazer como fator de proteção da saúde mental. Rev. Ciênc Med., 12(2) 163-172.

- Ribas, J. B. C. (1995). Viva a Diferença. Convivendo Com Nossas Restrições ou Deficiências. São Paulo: Moderna, 1995.

- Souza, I. C. et al. (março de 2009). Assistência prestada pela enfermagem aos pacientes com doença mental. Webartigos. Recuperado de http://www.webartigos.com/artigos/assistenciaprestada-pela-enfermagem-aos-pacientes-comdoenca-mental/16066.

- Tinsley, H. E., Teaff, J.D., Colbs, S.L. \& Kaufman, N. (1985). A system of classifying leisure activities in tnerms of psychological benefits of participatin reportede by older persons. J. gerentol, 40(2) 72-78. 